\title{
CFD Analysis of Sloshing within a Tank with Porous Baffles
}

\author{
V. Tejashwar Reddy \\ U.G Student, B-Tech $3^{\text {rd }}$ year, Department of Mechanical Engineering, 1, Rajiv Gandhi Salai, Old Mahabalipuram Road,Padur, \\ Kelambakkam, Chennai, Tamil Nadu 603103
}

\begin{abstract}
In fluid dynamics, sloshing refers to the movement of liquid inside another object. The liquid must have a free surface to constitute a slosh dynamics problem. The sloshing effect on a linearly moving partially filled diesel tank is studied using computational fluid dynamics with volume of fluid along with $k$-epsilon turbulence model to determine the sloshing behavior in the tank. In this study sloshing behavior of diesel fluid inside the tankis significantly reduced by using porous baffles. In this study, porous bed type porous model in fluent setup is used for defining porous nature of baffles. Two vertical transverse porous baffles are used in this study. Comparison of pressure acting on the front wall of the tanker for both the models i.e. one without any baffles and one with two transverse porous baffles is done in this study. The pressure vs. time plots of both the cases are plotted using $x$-y plots.
\end{abstract}

Keywords: sloshing, computational fluid dynamics, volume of fluids, porous baffles

\section{Introduction}

Any sudden change of motion of movingroad tanker vehicle which has a tank partially filled with a fluid causes sloshing, i.e. the motion of free surface of fluid inside the tank. Sloshing is an undesirable phenomenon because it reduces the stability of the vehicle which in turn can cause accidents which may lead to fire explosions if the tank has inflammable liquids such as diesel, petrol, kerosene. Several experiments have been performed to study the behavior of liquid sloshing and several alternative models were proposed to reduce the amplitude of sloshing within the tank. Several previous studies also hinted that the usage of porous transverse baffles or perforated baffles with large number of small openings or holes reduces the sloshing phenomenon. In this study "porous-bed" type porous model is being used to define the porous nature of transverse baffles. The pressure acting on the front wall of the tank is found to be reduced significantly.

\subsection{Sloshing}

In fluid dynamics, sloshing is movement of the free surface of the liquid inside the partially filled tanker. It is a common phenomenon that occurs in space craft tanks, fuel tanks of cargo ships, and trucks which transport fuels or water. Sloshing is an undesirable phenomenon which occurs in nuclear reactors during an earthquake. Hence the slosh forces or pressures inside the nuclear reactor storage

Tanks must be reduced to prevent dangerous accidents. Hence from the examples mentioned above sloshing motion must be controlled to prevent undesirable accidents and much research is to be carried out to reduce the slosh phenomenon.

\subsection{Reasons for sloshing phenomenon in a tank}

Sloshing inside a tank with liquid is caused due to two major reasons, they are

1) Sudden change of motion of vehicle such as sudden braking.
2) Sharp road turnings which may cause roll-over accidents.

Based on these two major reasons of sloshing in a tank, several experiments have been carried out to study the behavior of sloshing inside the tank and also several methods to reduce the sloshing phenomenon or the slosh loads on the tanker walls are proposed. Several authors proposed unique baffle designs and tanker shapes to reduce the phenomenon of sloshing.

\subsection{Factors which determine the sloshing intensity}

Several factors influence the intensity of sloshing of liquid inside the moving tank such as,

1) Liquid fill depth

2) Tank geometry

3) Type of liquid

4) Tank motion

\section{Literature Review}

Several people made several studies on the phenomenon of tank sloshing and proposed several alternatives to reduce the sloshing phenomenon. Some people have done experimental analysis while some have done powerful software tools such as computational fluid dynamics to study the phenomenon of sloshing. Some major studies related to this study are listed below.

\subsection{Numerical and Experimental approach}

Biswal et al. They used thin annular circular shaped baffle to reduce sloshing in a partially filled cylindrical tank.

Celebi et al. used a rectangular tank with vertical baffle partially filled with water. They solved Navier-Stokes equations by using FDM assumptions. VOF method was used to demonstrate the freesurface. The result showed that the usage of vertical baffles reduced the sloshing. 


\section{International Journal of Science and Research (IJSR) \\ ISSN (Online): 2319-7064}

Index Copernicus Value (2016): 79.57 | Impact Factor (2015): 6.391

\subsection{Computational Study}

Kingsley et al. studied about design and optimization of 3-D rectangular container for sloshing and impact using VOF technique. They performed the investigation using numerical simulation as well as experimental validation for numerical simulation user defined functions (UDF) was used to impose acceleration to the container.

A. Di Nardo et al. evaluated the behavior of liquid fuel storage tanks of cylindrical shapes $($ diameter $=10 \mathrm{~m}$, height $=$ $11 \mathrm{~m})$ when subjected to an earthquake. The analysis was done with the help of CFD software. The simulations were made for different filling levels, subjecting to 7 different acceleration inputs. Results are presented and show that sloshing of fluid depends on excitation frequency and filling levels.

\section{Geometric Model Description}

In this study a 3-dimensionalbasic elliptical tank scale down model of dimensions $0.2 \mathrm{~m}$ height, $0.8 \mathrm{~m}$ length, and $0.3 \mathrm{~m}$ width is produced using design modeler in the ANSYS FLUENT v.15.0. Two elliptical baffles are also modelled which are placed inside the tank at a distance of $0.266 \mathrm{~m}$ and $0.533 \mathrm{~m}$ respectively from front wall of the tank. Model tank volume is 0.1508 (S.I units).

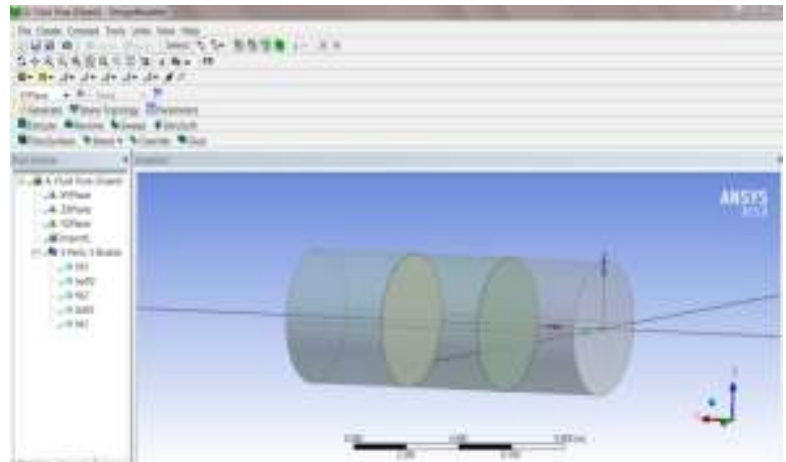

Figure 3.1: Tanker geometry modeled in ANSYS FLUENT v.15.0 design modeler

\section{Mesh Generation}

After creation of geometry, meshing is done in meshing tool. In this case uniform tetrahedral mesh is generated. The maximum skewness is 0.506 and average skewness is 0.24 which means mesh has minimum error. Mesh dependency has also been carried out and two cases were studied, one with 12,740 elements and other with 25,900 elements. In both the simulations the error was around 5 to $6 \%$, and hence the model is mesh independent.

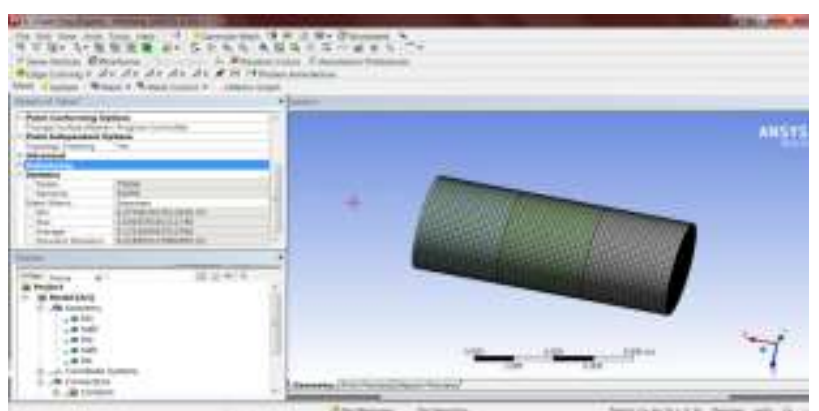

Figure 4.1: Meshing of tank

\section{Fluent Setup and Solution}

After meshing the mesh file is exported to CFD codeFLUENT. In this study $3-\mathrm{D}$, double precision fluent solvers with serial processing is used. The procedure followed is

1) In setup, mesh quality is checked.

2) Pressure based transient solver is used with explicit mode and gravity is enabled.

3) Turbulent model is considered and multiphase VOF method is used.

4) Air and diesel (liquid) are being used as primary and secondary phases respectively and aluminum as solid material for tank.

5) In boundary conditions module, the two baffles are defined as porous materials.

6) In the cell zone conditions of porous baffles, using Ergun's equation both viscous resistance $\left(1 / \mathrm{m}^{\wedge} 2\right)$ and inertial resistance $(1 / \mathrm{m})$ of porous medium were found out by taking void fraction to be 0.25 and mean particle diameter as $7.5 \mathrm{~mm}$

7) The inertial resistance is the permeability of the porous medium

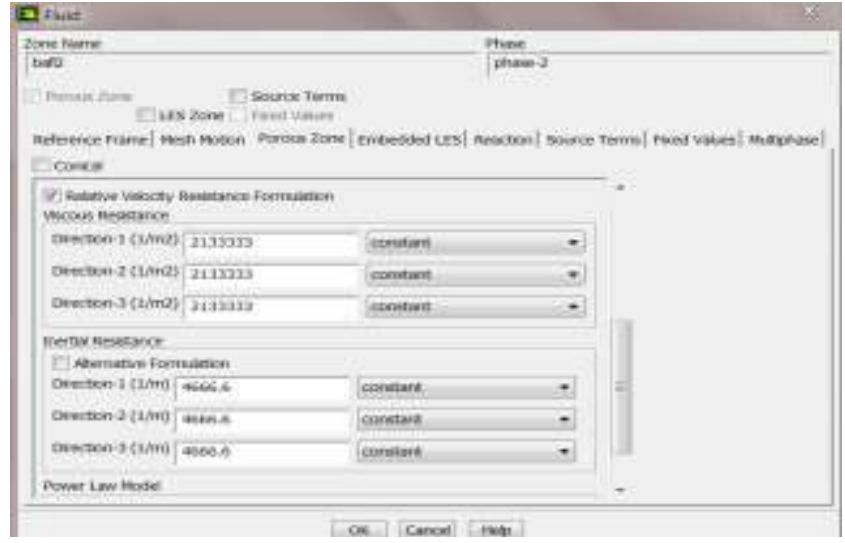

Figure 5.1: Cell zone condition for Porous baffles (interior)

8) Variable acceleration is given to the front wall of the tank along negative $\mathrm{x}$-direction as follows,

- 0 to 2 seconds acceleration is given as 15 (S.I units).

- 2 to 4 seconds acceleration is 0 and hence the tank moves with a constant velocity of $30 \mathrm{~m} / \mathrm{s}$.

- 4 to 6 seconds a constant deceleration of 15(S.I units) is given to the tank.

- Gravitational acceleration is given along positive zdirection as 9.81(S.I units)

Volume 6 Issue 12, December 2017 


\section{International Journal of Science and Research (IJSR) \\ ISSN (Online): 2319-7064 \\ Index Copernicus Value (2016): 79.57 | Impact Factor (2015): 6.391}

5.1 The properties of liquid diesel used is given below (in S.I. units)

Table 1: Properties of fluid-liquid diesel

\begin{tabular}{|c|c|}
\hline Density & Viscosity \\
\hline 730 & 0.0024 \\
\hline
\end{tabular}

5.2 Following solution method is adopted

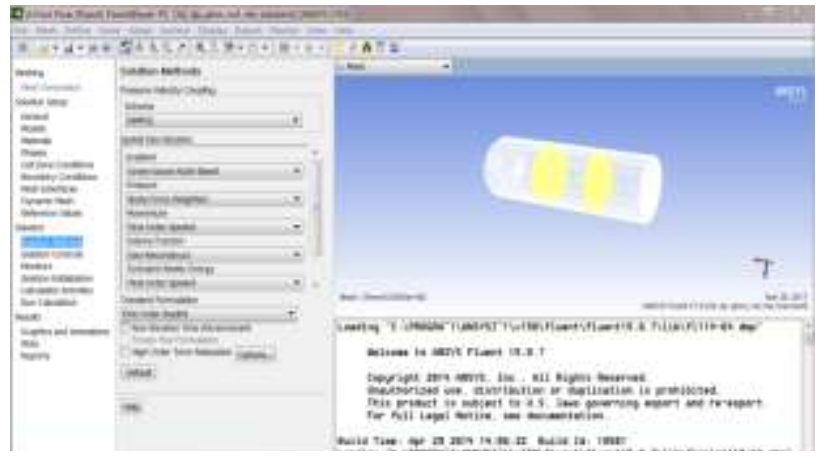

Figure 5.2: Solution method adopted

1) Pressure velocity coupling:SIMPLE

2) Gradient: Green gauss node based

3) Pressure: Body force weighted

4) Momentum: Power law

5) Volume fraction: Geo-Reconstruct

6) Transient Formulation: Fixed time step method.

7) For filling of diesel in tank, region cell is adapted and then adapted cell is patched by diesel liquid for $50 \%$ fill volume of the tank.

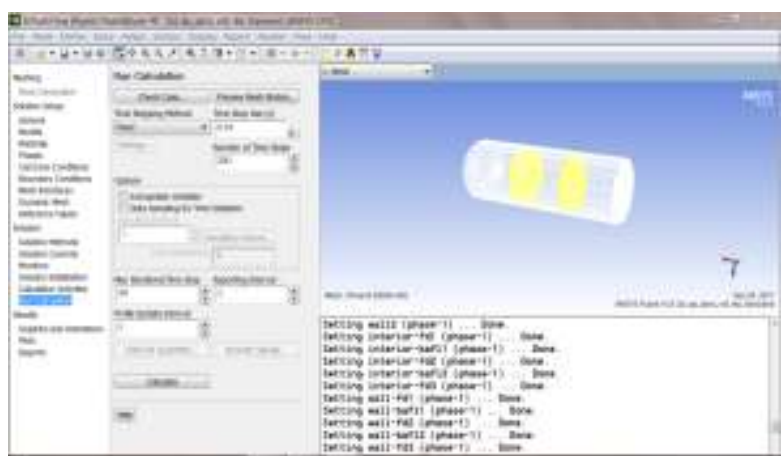

Figure 5.3: Fixed time step formulation

8) Time step size is set as 0.01 seconds and number of time steps is fixed as 600 and total time of simulation is 6 seconds.

9) In this study porous-bed model is used to define porous nature of the baffles, which is available in the CFD package.

10)In the real world application "Aluminum foam" material with the same permeability, appropriate void space and porosity can be used. The properties of aluminum foam material which can be used for baffles to give the similar pressure drop as that of "porous-bed" model used in the CFD package is given below.

Table 2: Properties of material used for porous baffles

\begin{tabular}{|c|c|c|}
\hline Material & $\begin{array}{c}\text { Permeability(k) } \\
\text { (S.I units) }\end{array}$ & $\begin{array}{c}\text { \% of void } \\
\text { space }\end{array}$ \\
\hline $\begin{array}{c}\text { Aluminum (Open cell } \\
\text { foam) (Al-6101) }\end{array}$ & $4.6875 \mathrm{e}-7$ & 91 \\
\hline
\end{tabular}

\subsection{Process of manufacturing}

The aluminum foam porous baffle can be manufactured by powder metallurgy process or casting process. Both the process are not expensive, and desired material with desired properties can be manufactured.
Advantages of open-cell aluminum porous material
1. High surface area
2. High specific stiffness
3. Low pressure drop
4. Controllable pore size while manufacturing

\section{Results and Discussion}

6.1 The volume fraction contours on tank wall are obtained in CFD post are shown below.

\section{CASE1: Tank without baffles}

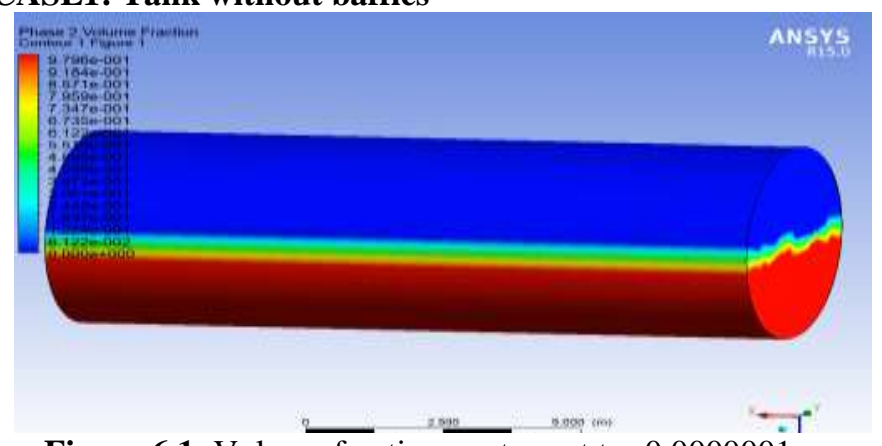

Figure 6.1: Volume fraction contour at $\mathrm{t}=0.0000001$ seconds

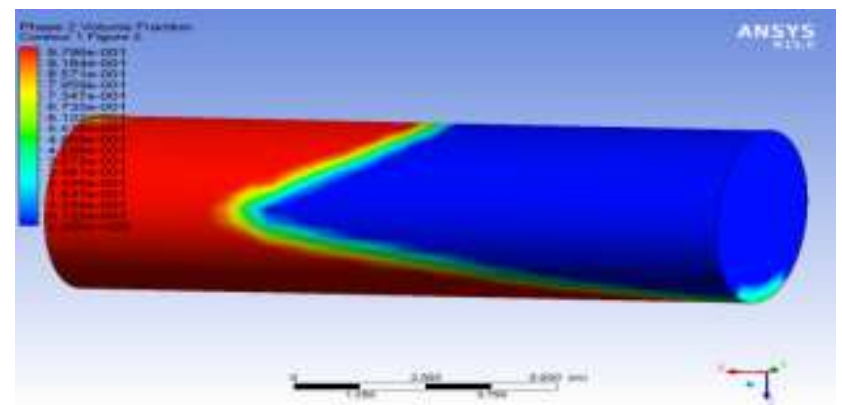

Figure 6.2: Volume fraction contour at $\mathrm{t}=1 \mathrm{~second}$

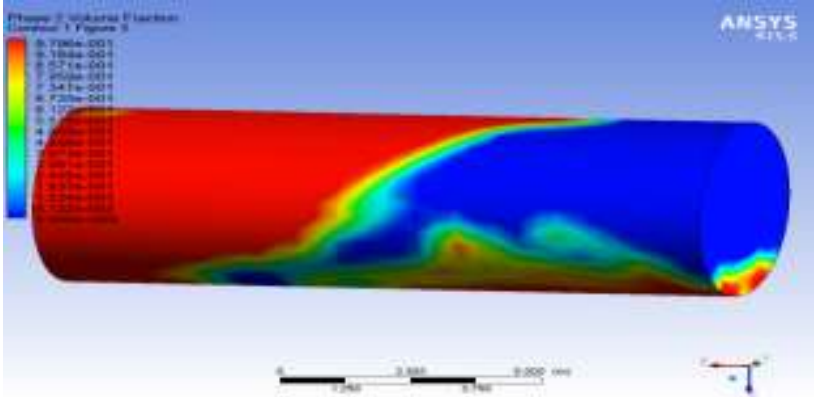

Figure 6.3: Volume fraction contour at $\mathrm{t}=2$ second 


\title{
International Journal of Science and Research (IJSR)
}

ISSN (Online): 2319-7064

Index Copernicus Value (2016): 79.57 | Impact Factor (2015): 6.391
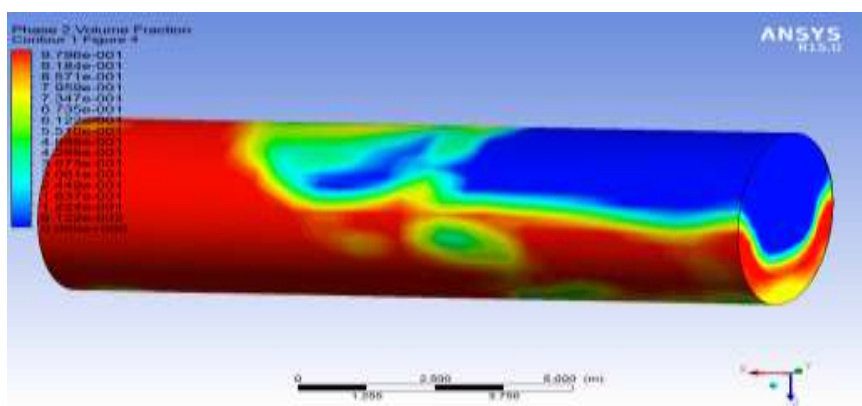

Figure 6.4: Volume fraction contour at $\mathrm{t}=3$ second

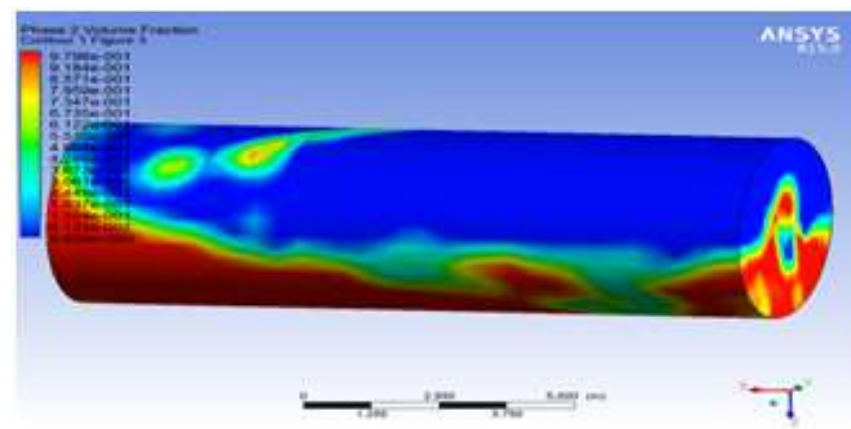

Figure 6.5: Volume fraction contour at $\mathrm{t}=4$ seconds
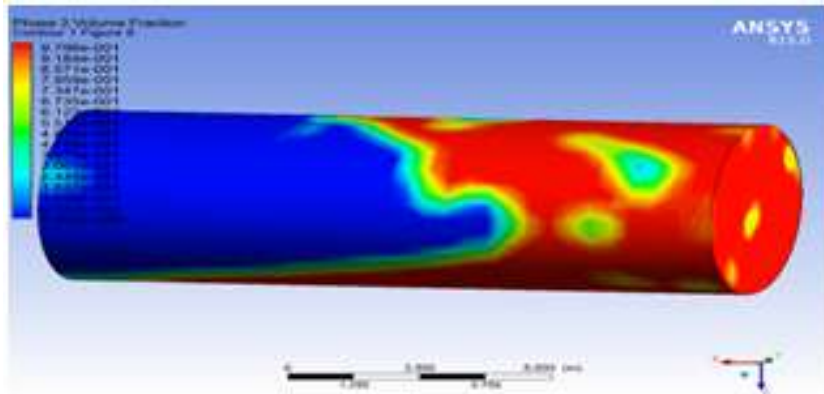

Figure 6.6: Volume fraction contour at $\mathrm{t}=5$ second

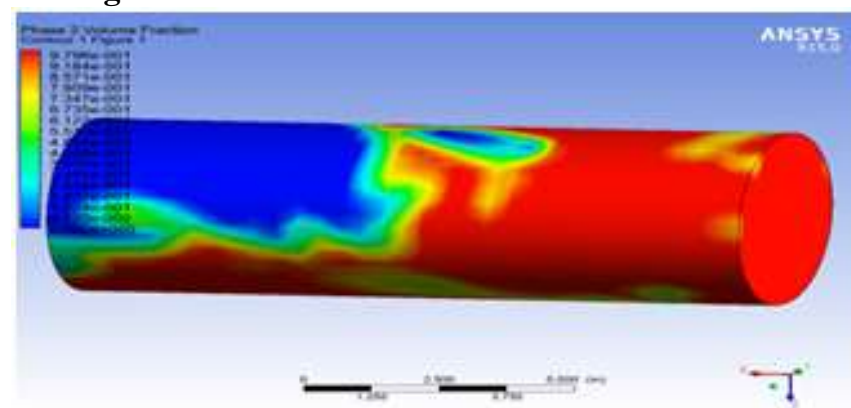

Figure 6.7: Volume fraction contour at $\mathrm{t}=6$ second

\section{CASE 2: Tank with porous baffles}

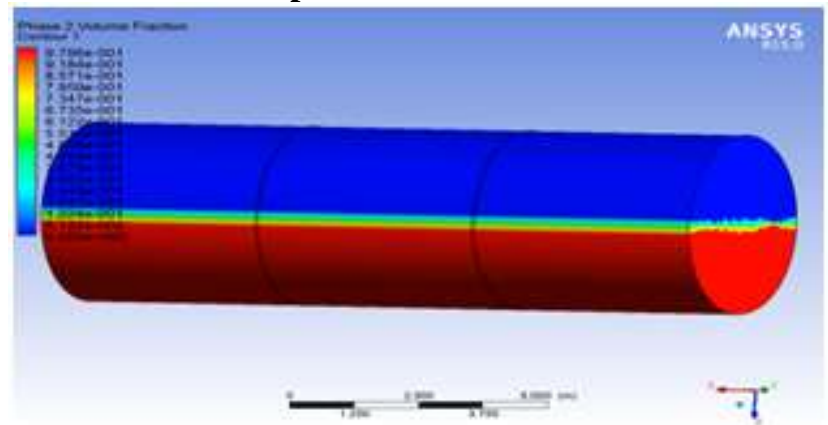

Figure 6.8: Volume fraction contour at $\mathrm{t}=0.0000001$ second

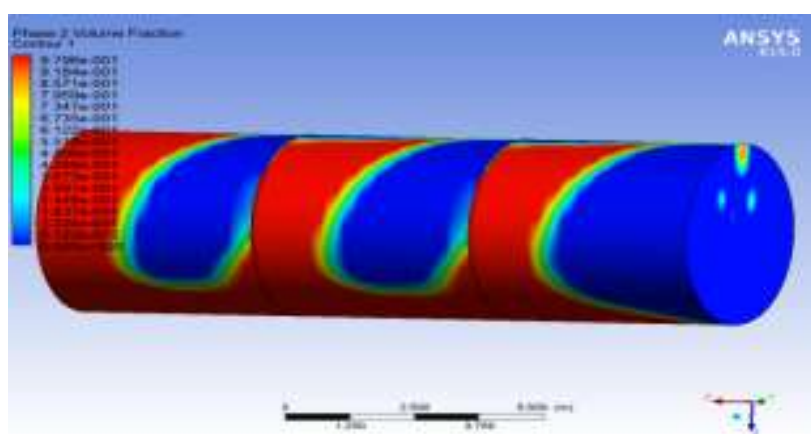

Figure 6.9: Volume fraction contour at $\mathrm{t}=1$ second

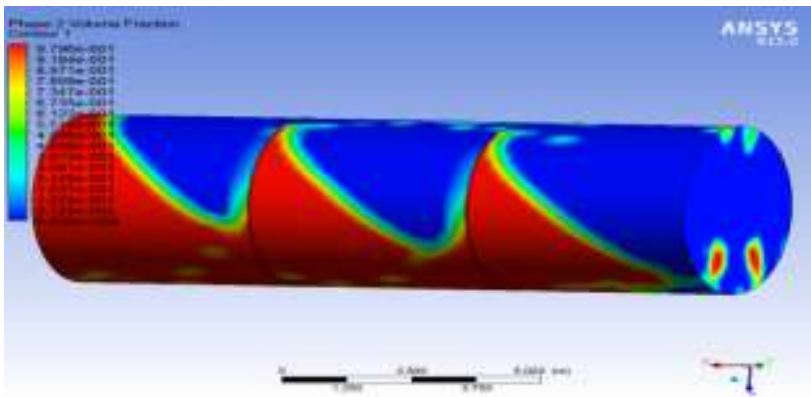

Figure 6.10: Volume fraction contour at $\mathrm{t}=2$ second

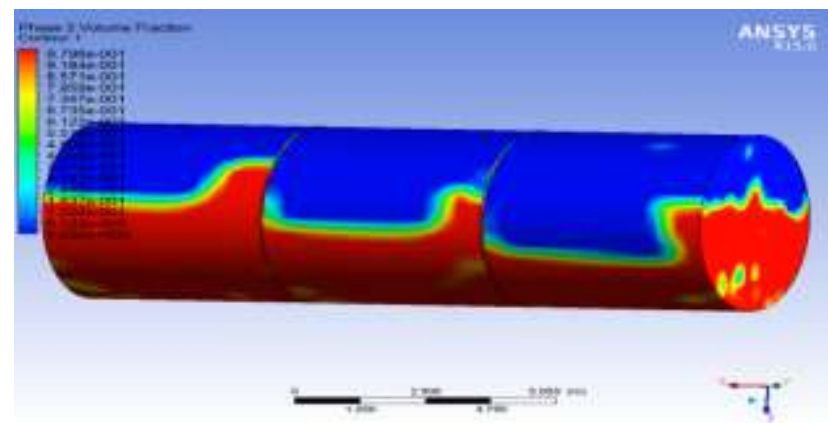

Figure 6.11: Volume fraction contour at $\mathrm{t}=3$ second

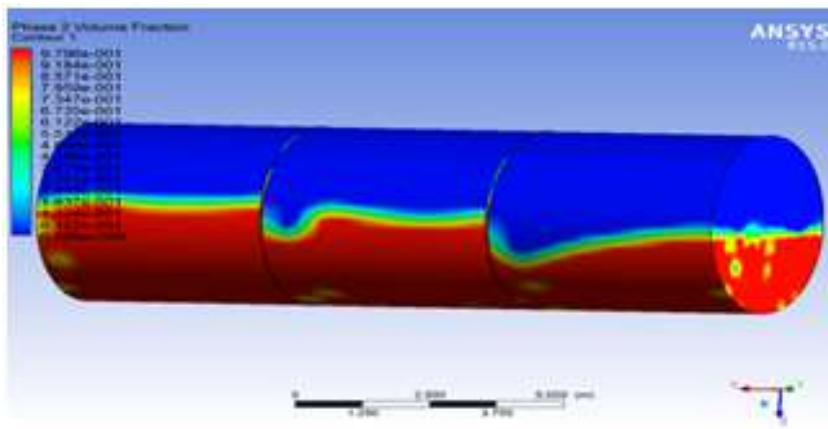

Figure 6.12: Volume fraction contour at $\mathrm{t}=4$ second

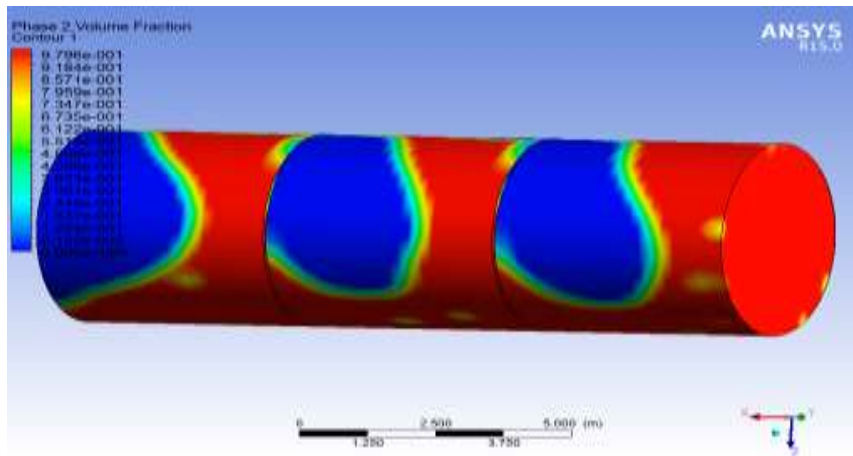

Figure 6.13: Volume fraction contour at $t=5$ second

Volume 6 Issue 12, December 2017

\author{
www.ijsr.net
}

Licensed Under Creative Commons Attribution CC BY 


\section{International Journal of Science and Research (IJSR) \\ ISSN (Online): 2319-7064}

Index Copernicus Value (2016): 79.57 | Impact Factor (2015): 6.391

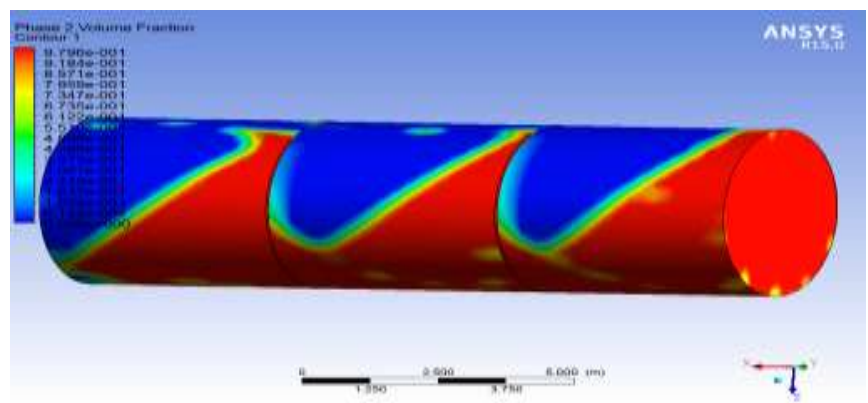

Figure 6.14: Volume fraction contour at $t=6$ second

6.2 CASE 1: Following figure shows the graph between longitudinal forces along $x$-direction vs. time, for $50 \%$ fill condition without baffles

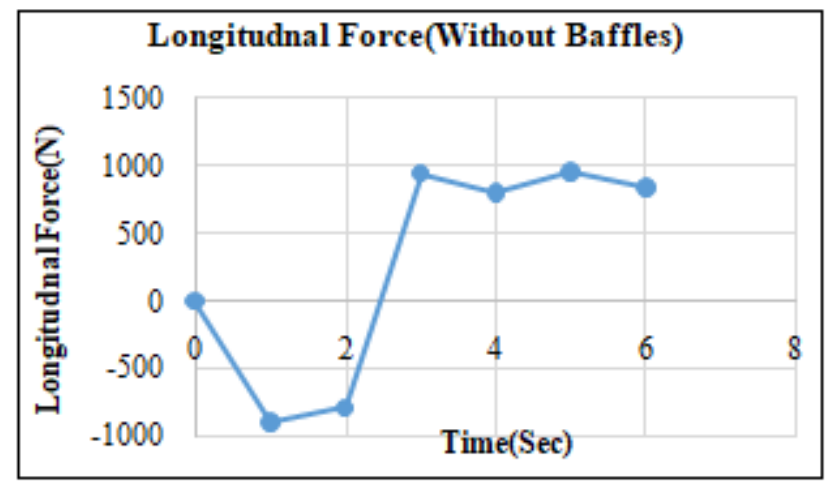

Figure 6.15: longitudinal force along $\mathrm{x}$-direction at $50 \%$ fill condition without baffles

CASE 2: Graph between longitudinal forces along $x-$ direction vs. time, for $\mathbf{5 0 \%}$ fill condition with two vertical transverse porous baffles

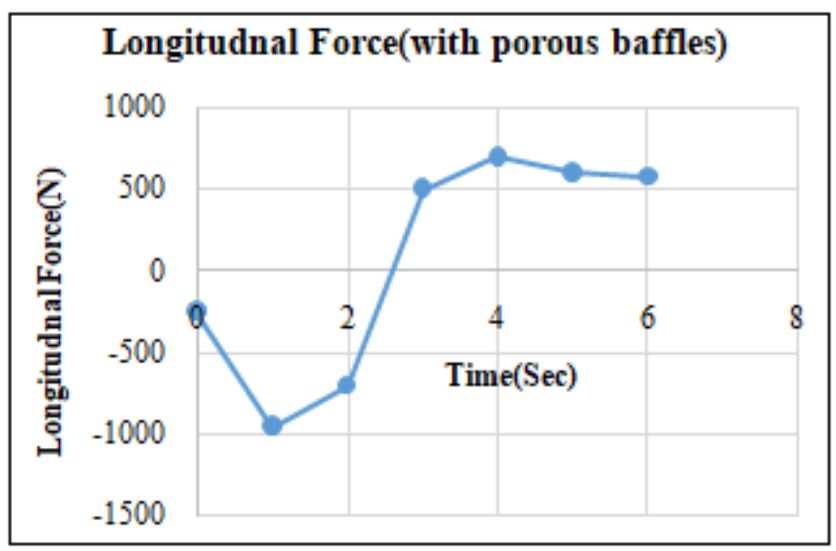

Figure 6.16: longitudinal force along $\mathrm{x}$-direction at $50 \%$ fill condition with porous baffles

Hence by examining the volume fraction contours in both the cases i.e. for no baffle case and for baffled case, it is evident that the sloshing intensity has been significantly reduced and further $x-y$ plots have also been generated to validate the above argument.

The figures 6.15 and 6.16 show the plots drawn between time in seconds on $\mathrm{x}$-axis and longitudinal forces taken on $\mathrm{y}$ axis. The maximum sloshing force in longitudinal direction was found to be $965.39 \mathrm{~N}$ at $\mathrm{t}=5 \mathrm{sec}$
Whereas the maximum longitudinal sloshing forces for baffled case is found to be $702.96 \mathrm{~N}$ at $\mathrm{t}=4 \mathrm{sec}$. Hence the sloshing forces are found to be reduced significantly by using porous baffles. The main advantage of usage of porous baffles instead of normal vertical transverse baffle plates with a single central hole is that, since porous material has large number of small openings or void spaces the pressure or forces acting on the baffle wall can be reduced and thereby increasing the lifetime of baffle without causing any failure, further more porous material like open cell metal foam has higher strength, low pressure drop and controllable pore size while manufacturing.

\section{Conclusion}

The fluid liquid diesel is subjected to oscillations inside the tank with gravitational acceleration $9.81 \mathrm{~m} / \mathrm{s}^{\wedge} 2$ and variable acceleration given to front wall of the tanker for a period of 6 seconds.

Many investigations and models studied the sloshing phenomenon in tankers and proposed various models to reduce the sloshing forces inside the tanker.

In this study computational fluid dynamics is used to study the sloshing phenomenon and longitudinal forces acting inside the tank for both the cases of without baffles and with transverse vertical porous baffles. The sloshing forces induced inside the tank are found to be significantly reduced using porous baffles by studying the plotted graphs between time (in seconds) and longitudinal force (in newton.) in figure 6.15 and figure 6.16. And the elliptical geometry of the tank used in this study has a major influence in reducing sloshing inside the tank.

\section{Future Scope}

This study is mainly done considering the sloshing phenomenon in space crafts, road tanker vehicles, aero planes, and high speed racing cars. So, future research can be carried out to further reduce sloshing impact forces acting inside the tank.

\section{References}

[1] A. Cariou, and G. Casella. "Liquid Sloshing in Ship Tanks: a Comparative Study of Numerical simulation", Marine Structures, Vol. 12, pp. 183-198, 1999.

[2] Puneet Kumar Nema, (2014) "Computational study of sloshing behavior in 3-D rectangular tank with and without baffle under Seismic Excitation" Dissertation, presented to N. I. T Rourkela in partial fulfillment of the requirements for the degree of M.Tech, [5, pp. 23-27].

[3] P.K. Panigrahy, U.K. Saha, D. Maity 2009. "Experimental studies on sloshing behavior due to horizontal movement of liquids in baffled tanks." Ocean Engineering [36, pp. 213-222.]

[4] A.T. Chwang, and K.H. Wang. "Nonlinear Impulsive Force on an Accelerating Container" J. of Fluids Eng., Vol. 106, pp. 233-240, 1984.

[5] KritThreepopnartkul, ChakritSuvanjumrat, "The Effect of Baffles on Fluid Sloshing inside the Moving

Volume 6 Issue 12, December 2017 


\section{International Journal of Science and Research (IJSR) \\ ISSN (Online): 2319-7064}

Index Copernicus Value (2016): 79.57 | Impact Factor (2015): 6.391

Rectangular Tank", Journal of Research and Applications in Mechanical Engineering. [Vol. 1 No.2].

[6] Effect of baffles on a partially filled cubic tank: Numerical simulation and experimental validation $\mathrm{M}$. Eswarana, U.K. Saha, D. Maity Department of Mechanical Engineering, Indian Institute of Technology Guwahati, Guwahati 781 039, Assam, India Department of Civil Engineering, Indian Institute of Technology Kharagpur, Kharagpur 721 302, West Bengal, India.

[7] IS 13187 (1991) "Road tankers for light petroleum products" Chemical Engineering Plants and Related Equipment [15, pp. 1-2].

[8] T. Kandasamy, S. Rakheja, A.K.W. Ahmed, (2010), "An Analysis of Baffles Designs for Limiting Fluid Slosh inPartly Filled Tank Trucks", The Open Transportation Journal. [Vol. 4: 23-32].

Volume 6 Issue 12, December 2017

www.ijsr.net 